\title{
Biomechanical evaluation of lateral lumbar interbody fusion with secondary augmentation
}

\author{
Marco T. Reis, MD, ${ }^{1}$ Phillip M. Reyes, BSE, ${ }^{1}$ Idris Altun, MD, ${ }^{1}$ Anna G. U. S. Newcomb, MS, ${ }^{2}$ \\ Vaneet Singh, MS, ${ }^{3}$ Steve W. Chang, MD, ${ }^{1}$ Brian P. Kelly, PhD, ${ }^{2}$ and Neil R. Crawford, PhD ${ }^{2}$
}

\begin{abstract}
${ }^{1}$ Department of Neurosurgery, Barrow Neurological Institute, St. Joseph's Hospital and Medical Center; ${ }^{2}$ Spinal Biomechanics Laboratory, Department of Neurosurgery Research, St. Joseph's Hospital and Medical Center, Phoenix, Arizona; and 3Medtronic, Inc., Memphis, Tennessee
\end{abstract}

\begin{abstract}
OBJECTIVE Lateral lumbar interbody fusion (LLIF) has emerged as a popular method for lumbar fusion. In this study the authors aimed to quantify the biomechanical stability of an interbody implant inserted using the LLIF approach with and without various supplemental fixation methods, including an interspinous plate (IP).
\end{abstract}

\begin{abstract}
METHODS Seven human cadaveric L2-5 specimens were tested intact and in 6 instrumented conditions. The interbody implant was intended to be used with supplemental fixation. In this study, however, the interbody was also tested without supplemental fixation for a relative comparison of these conditions. The instrumented conditions were as follows: 1) interbody implant without supplemental fixation (LLIF construct); and interbody implant with supplemental fixation performed using 2) unilateral pedicle screws (UPS) and rod (LLIF + UPS construct); 3) bilateral pedicle screws (BPS) and rods (LLIF + BPS construct); 4) lateral screws and lateral plate (LP) (LLIF + LP construct); 5) interbody LP and IP (LLIF + LP + IP construct); and 6) IP (LLIF + IP construct). Nondestructive, nonconstraining torque (7.5 Nm maximum) induced flexion, extension, lateral bending, and axial rotation, whereas 3D specimen range of motion (ROM) was determined optoelectronically.
\end{abstract}

RESULTS The LLIF construct reduced ROM by $67 \%$ in flexion, $52 \%$ in extension, $51 \%$ in lateral bending, and $44 \%$ in axial rotation relative to intact specimens $(p<0.001)$. Adding BPS to the LLIF construct caused ROM to decrease by $91 \%$ in flexion, $82 \%$ in extension and lateral bending, and $74 \%$ in axial rotation compared with intact specimens $(p<$ 0.001), providing the greatest stability among the constructs. Adding UPS to the LLIF construct imparted approximately one-half the stability provided by LLIF + BPS constructs, demonstrating significantly smaller ROM than the LLIF construct in all directions (flexion, $p=0.037$; extension, $p<0.001$; lateral bending, $p=0.012$ ) except axial rotation $(p=0.07)$. Compared with the LLIF construct, the LLIF + LP had a significant reduction in lateral bending $(p=0.012)$, a moderate reduction in axial rotation $(p=0.18)$, and almost no benefit to stability in flexion-extension $(p=0.86)$. The LLIF + LP + IP construct provided stability comparable to that of the LLIF + BPS. The LLIF + IP construct provided a significant decrease in ROM compared with that of the LLIF construct alone in flexion and extension ( $p=0.002)$, but not in lateral bending $(p=0.80)$ and axial rotation $(p=0.24)$. No significant difference was seen in flexion, extension, or axial rotation between LLIF + BPS and LLIF + IP constructs.

CONCLUSIONS The LLIF construct that was tested significantly decreased ROM in all directions of loading, which indicated a measure of inherent stability. The LP significantly improved the stability of the LLIF construct in lateral bending only. Adding an IP device to the LLIF construct significantly improves stability in sagittal plane rotation. The LLIF + LP + IP construct demonstrated stability comparable to that of the gold standard $360^{\circ}$ fixation (LLIF + BPS).

http://thejns.org/doi/abs/10.3171/2016.4.SPINE151386

KEY WORDS biomechanics; interspinous plate; lateral lumbar interbody fusion; lateral plate; pedicle screw; range of motion

$\mathrm{T}$ HE effects of adding an interbody implant to posterolateral fusion in the treatment of spinal disorders have been studied extensively. Some of the reported advantages include increased fusion rates and decreased revision surgeries. ${ }^{15}$ The reported disadvan- tages include increased complication rates and increased blood loss. ${ }^{18}$ Several techniques have been described for interbody fusion, such as posterior lumbar interbody fusion (PLIF), anterior lumbar interbody fusion (ALIF), and transforaminal lumbar interbody fusion (TLIF) ${ }^{26}$

ABBREVIATIONS ALIF = anterior lumbar interbody fusion; BPS = bilateral pedicle screws; IP = interspinous plate; LLIF = lateral lumbar interbody fusion; LP = lateral plate; PLIF = posterior lumbar interbody fusion; ROM = range of motion; TLIF = transforaminal lumbar interbody fusion; UPS = unilateral pedicle screws.

SUBMITTED November 25, 2015. ACCEPTED April 5, 2016.

INCLUDE WHEN CITING Published online July 8, 2016; DOI: 10.3171/2016.4.SPINE151386. 
Biomechanical results with an interbody implant inserted using the ALIF approach have been controversial, with some studies suggesting that the interbody implant alone does not provide strong segmental stability in extension, axial rotation, or lateral bending, and that posterior supplemental fixation may be necessary to achieve good stability. ${ }^{21,23,30,33,38}$ When comparing interbody implant insertion using an anterior versus a lateral approach, several authors have shown the destabilizing effect of sectioning the anterior longitudinal ligament. . $^{17,18,34,40}$ Other biomechanical studies have shown the destabilizing effect of facetectomy/hemifacetectomy (unilateral or bilateral) used for posterior approaches, such as TLIF/PLIF. ${ }^{14,16,46}$ Sohn et al. ${ }^{37}$ and Tsantrizos et al. ${ }^{42}$ demonstrated the effects of geometry and the size of implants on spinal stability, and they concluded that rectangular and large interbody implants produce better results than cylindrical and small implants by capturing the periphery of the endplate, which is stronger than the core area. Similarly, in a retrospective study of 53 patients, Subach et al. ${ }^{39}$ reported that a wider implant placement significantly reduced the amount of subsidence compared with a conventional narrower placement. Although further studies are needed to assess the biomechanical properties of interbody implants in vivo, the combination of these results led to the hypothesis that a large rectangular interbody implant, inserted with preservation of the anterior longitudinal ligament, could offer improved biomechanical performance over alternative lumbar interbody fusion techniques (i.e., ALIF, TLIF, or PLIF).

A variation of the lateral retroperitoneal surgical approach to the lumbar spine, called lateral lumbar interbody fusion (LLIF), has gained favor as an alternative to achieve fusion, either with or without secondary instrumentation. ${ }^{1,4,10,11,19,22,26,28,45}$ This approach uses advanced lighting and retraction systems to minimize the exposure and soft-tissue damage that occur in the lateral retroperitoneal approach. Relatively few biomechanical studies have evaluated the stability of an interbody fusion construct with and without additional anterior or posterior instrumentation inserted using this approach. 2,5,12,13,31,32

This study aimed to evaluate the stability of an interbody fusion construct by using the LLIF approach with and without supplemental pedicle screw-rod, anterolateral plate, and/or interspinous plate (IP) instrumentation. We hypothesized that the large footprint of the interbody implant used in the LLIF approach may provide a biomechanical advantage toward creating a favorable, stable environment for bone fusion.

\section{Methods}

Seven unembalmed human cadaveric L2-5 specimens were studied. The donor age ranged from 40 to 73 years (median 58 years); 6 were female and 1 was male. Specimens were carefully cleaned of muscle tissue without damaging any ligaments, discs, or joint capsules. Plain film radiographs were obtained, and any available medical history was inspected to ensure that no specimen had any obvious radiographic flaws, visible flaws, or flaws noted on patient history (especially metastatic disease, osteophytes, disc narrowing, or joint arthrosis). Wood screws were inserted in various locations in the exposed L-5 endplate, and facet articulations and screwheads were embedded in a molded block of polymethylmethacrylate for rigid attachment to the base of the testing apparatus. Similarly, screws were inserted in the exposed L-2 endplate and facet articulations, and these in turn were potted in polymethylmethacrylate for mechanical application of loads.

Although the interbody implant tested in this study is intended to be used with supplemental fixation, the implant was also tested without supplemental fixation to allow a relative comparison of these conditions. The L3-4 angular range of motion (ROM) of each test specimen was evaluated in the following fixation configurations.

1) Intact condition.

2) Interbody implant using LLIF approach (LLIF construct).

3) Interbody implant plus unilateral pedicle screws (UPS) and rod using LLIF approach (LLIF + UPS construct).

4) Interbody implant plus bilateral pedicle screws (BPS) and rods using LLIF approach (LLIF + BPS construct).

5) Interbody implant plus lateral screws and lateral plate (LP) using LLIF approach (LLIF + LP construct).

6) Interbody implant plus LP plus IP using LLIF approach ( LLIF + LP + IP construct).

7) Interbody implant plus IP using LLIF approach (LLIF + IP).

In the testing sequence, the order of steps 3 and 4 was reversed in 3 of 7 specimens to help mitigate potential bias due to testing order. To obviate the need to interrupt testing to remove the specimen from its upright mounting on the test frame for pedicle screw-rod instrumentation and lateral screw-plate application, we inserted pedicle and lateral screws before step 2 but left them disconnected from rods and plates (Fig. 1). Such treatment was not thought to have any relevant effect on biomechanical outcomes, because screws independent of rods and plates should not restrict motion or loosen in any significant way. If there were some unanticipated effect from the independent pedicle or lateral screws, it would be controlled for by having the screws in place for each of the testing directions that followed for all specimens.

The interbody implant used in the LLIF approach (CLYDESDALE Spinal System; Medtronic, Inc.) was available in heights ranging from 8 to $16 \mathrm{~mm}$ and widths ranging from 40 to $60 \mathrm{~mm}$. Fluoroscopy was used to select the implant size in the same manner as would be done clinically, avoiding overdistraction of the disc space and selecting cage width so as to span the entire vertebral body width from left to right. The vertebral body was divided into 4 quarters from anterior to posterior in a lateral view, with the midpoint of the device placed within the second quarter. In the current study, interbody height varied from 10 to $14 \mathrm{~mm}$ and width varied from 50 to 60 $\mathrm{mm}$. The pedicle screws used (CD HORIZON SOLERA Spinal System; Medtronic, Inc.) were $6.5 \mathrm{~mm}$ in diameter, with length ranging from 45 to $55 \mathrm{~mm}$, depending on the size of the vertebral body. Screw length was selected in each specimen to span approximately two-thirds of the vertebral body. The trajectories of the pedicle screws were 


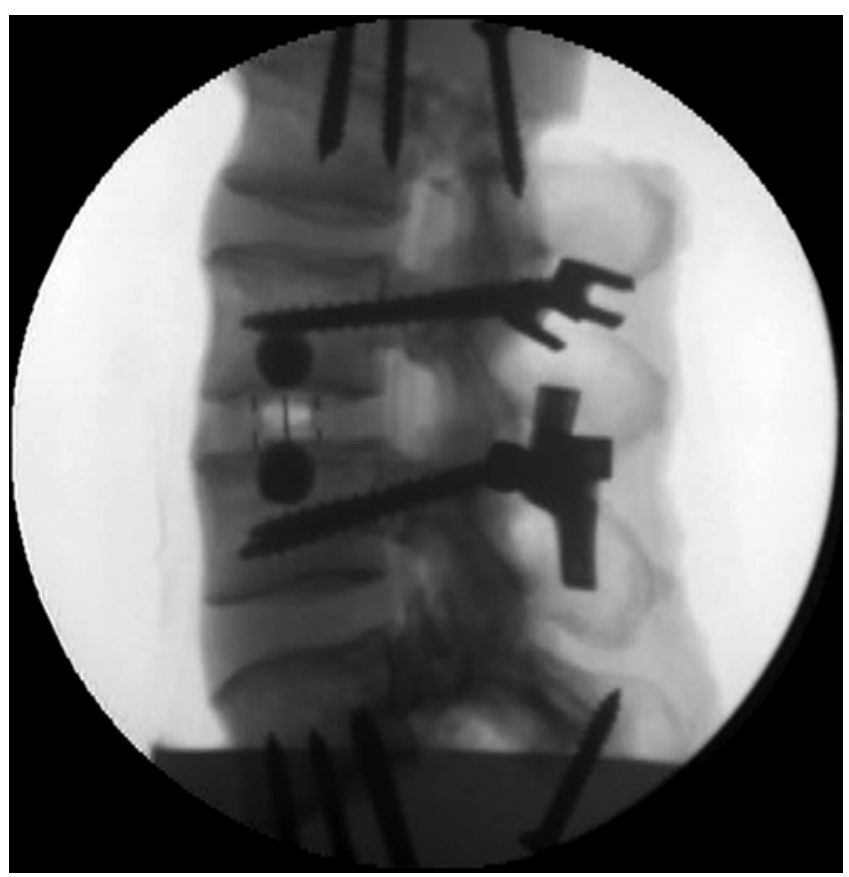

FIG. 1. Lateral radiograph of a specimen with pedicle screws, IP, LLIF, and lateral screws inserted. The rods and LP are detached.

planned to permit the insertion of the lateral screws in the vertebral body for plate attachment. The lateral screws (CD HORIZON ENGAGE Plate System; Medtronic, Inc.) were inserted bicortically, parallel to the adjacent endplate and perpendicular to the sagittal plane. The screw diameter used was $6.5 \mathrm{~mm}$, and length varied from 45 to 55 $\mathrm{mm}$. For IP stabilization, the SPIRE Z (Medtronic, Inc.) was used (Fig. 2). The IP wing length was $41 \mathrm{~mm}$. For insertion of the IP, the interspinous ligament was punctured and the supraspinous ligament was preserved. The plate was clamped and locked around the spinous processes by using the provided hand tool.

In all conditions for each test group, an apparatus was used in which a system of cables and pulleys imparted nondestructive, nonconstraining torque in conjunction with a standard servohydraulic test system. ${ }^{6}$ This type of loading is distributed evenly to each motion segment, regardless of the distance from the point of load application. ${ }^{29}$ Loads of $7.5 \mathrm{Nm}$ maximum were applied in the appropriate anatomical axes to induce 6 different types of motion: flexion, extension, left and right lateral bending, and left and right axial rotation. In each loading direction, 3 preconditioning cycles were applied at $7.5 \mathrm{Nm}$ for 60 seconds each, after which the specimen was allowed to rest at zero load for 60 seconds. During the data collection cycle, the load was applied quasistatically in $1.5-\mathrm{Nm}$ increments, with each incremental load held for 45 seconds, to a maximum of $7.5 \mathrm{Nm}$.

The 3D specimen motion in response to the applied loads during flexibility tests was determined using the Optotrak 3020 motion capture system (Northern Digital, Inc.). This system measured stereophotogrammetrically the 3D displacement of infrared-emitting markers rigidly attached in a noncollinear arrangement to each verte-
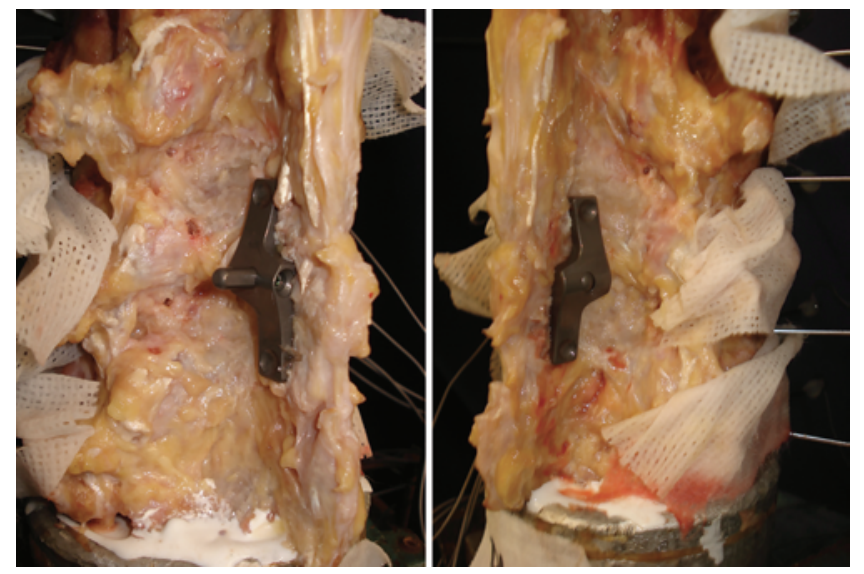

FIG. 2. Test specimen with an IP device at L3-4 shown from the posterolateral view (left) and right posterolateral view (right). Figure is available in color online only.

bra. Custom software converted the marker coordinates to angles with respect to each of the anatomical axes in terms of the motion segment's own coordinate system.? Spinal angles were calculated using a 3D technique that provides appropriate results for describing planar angles in the spine.?

From the raw data, the angular ROM at the instrumented level was quantified to assess stability. For unidirectional lateral bending or axial rotation, ROM was quantified as one-half of the difference of angles at opposing maximum loads. The ROM was assessed unidirectionally during flexion and extension by quantifying it from the center of the lax zone (the subset of ROM representing the zone of ligamentous laxity). The angles representing the outer boundaries of the lax zone were determined by linearly extrapolating load-displacement data points from within the elastic region of loading (angles at 4.5, 6.0, and $7.5 \mathrm{Nm}$ ) to zero load. ${ }^{8}$ Angular ROM data were statistically analyzed using a one-way repeated-measures ANOVA, followed by Holm-Š́dák tests used to determine whether the mean outcome measures were significantly different among the intact and 6 different instrumented conditions. Angular ROM was also normalized by dividing the ROM in the instrumented condition by the corresponding ROM in the intact condition for an additional comparison among the constructs tested.

\section{Results}

Table 1 provides specimen-specific information, including sex, age, and intact testing ROM. The mean normalized instrumented-level ROM data are shown graphically in Fig. 3 for visual comparison of all fixation constructs and all directions of testing. The mean absolute angular rotation values (in degrees) for the same level over all fixation constructs and directions of testing are summarized in Table 2. In all fixation conditions, the angular ROM was significantly reduced relative to the intact condition in all directions of loading $(\mathrm{p}<0.001)$.

For the interbody implant performed using the LLIF approach without any secondary supplementation, the 
TABLE 1. Summary of spinal test specimen donor age, sex, and mean intact L3-4 rotational ROM recorded during flexionextension, lateral bending, and axial rotation testing

\begin{tabular}{cccrcc}
\hline & & & \multicolumn{3}{c}{ Mean ROM $\left(^{\circ}\right)$} \\
\cline { 4 - 6 } Specimen & Sex & Age (yrs) & F/E & LB & AR \\
\hline DL01 & $F$ & 40 & 9.7 & 5.9 & 1.7 \\
\hline DL04 & M & 50 & 4.2 & 2.1 & 0.6 \\
\hline DL05 & F & 54 & 13.8 & 8.1 & 2.3 \\
\hline DL03 & F & 57 & 7.9 & 5.6 & 3.0 \\
\hline DL07 & F & 64 & 12.1 & 6.6 & 3.9 \\
\hline DL06 & $F$ & 65 & 11.4 & 5.8 & 3.3 \\
\hline DL02 & F & 73 & 8.5 & 5.8 & 4.1 \\
\hline
\end{tabular}

$A R=$ axial rotation; $F / E$ = flexion-extension; $L B=$ lateral bending.

mean angular ROM was significantly reduced-to $67 \%$ of the intact ROM during flexion, 52\% during extension, 51\% during lateral bending, and $44 \%$ during axial rotation ( $\mathrm{p}$ $<0.001$ ). Adding a UPS (LLIF construct vs LLIF + UPS construct) significantly reduced the angular ROM further, specifically by $45 \%$ during flexion $(\mathrm{p}=0.03), 46 \%$ during extension ( $\mathrm{p}<0.001)$, and $38 \%$ during lateral bending ( $\mathrm{p}=$ 0.012 ). Axial rotation was reduced by $32 \%$; however, this reduction was not statistically significant $(\mathrm{p}=0.07)$. The subsequent addition of a pedicle screw on the contralateral side (LLIF + BPS construct vs LLIF + UPS construct) further reduced angular ROM by $51 \%$ in flexion, $30 \%$ in extension, $40 \%$ in lateral bending, and $31 \%$ in axial rotation; however, all these reductions were less than $0.7^{\circ}$ and were not statistically significant. Of all the constructs tested, the LLIF + BPS construct was the most stable in all directions of loading (Table 2, Fig. 3), resulting in angular ROM reductions of $91 \%$ in flexion, $82 \%$ in extension and lateral bending, and $74 \%$ in axial rotation compared with the intact level.

The addition of an LP and screws to the LLIF construct (LLIF construct vs LLIF + LP construct) significantly decreased angular ROM during lateral bending by 38\% ( $\mathrm{p}=$ 0.01 ), moderately but not significantly reduced ROM by $24 \%$ in axial rotation $(\mathrm{p}=0.18)$, and had almost no influence on rotational stability during flexion and extension (Fig. 3). In contrast, ROM with the LLIF + LP construct was equivalent to that with the LLIF + UPS construct during lateral bending and axial rotation ( $p>0.60$, Fig. 3), but ROM was $75 \%$ greater during flexion $(\mathrm{p}=0.05)$ and $80 \%$ greater during extension $(\mathrm{p}=0.002)$.

Adding an IP to the LLIF + LP construct (i.e., LLIF + LP + IP construct) demonstrated an overall reduction in angular ROM that was comparable to that of the LLIF + BPS construct, with no statistically significant differences between the two constructs during any direction of loading $(p>0.16)$. The angular ROM with the LLIF + LP + IP construct was significantly reduced versus the LLIF + LP construct-by $70 \%$ during flexion $(\mathrm{p}=0.003)$ and by $60 \%$ during extension $(\mathrm{p}<0.001)$; but ROM was equivalent during lateral bending and axial rotation $(\mathrm{p}>0.35)$. After removal of the LP and screws (LLIF + LP + IP vs LLIF + IP constructs), the angular ROM significantly increased during lateral bending by $67 \%(\mathrm{p}=0.01)$, moderately increased by $31 \%$ during axial rotation, and remained almost unchanged during flexion and extension.

\section{Discussion}

In 2001, LLIF was introduced as a modification to the

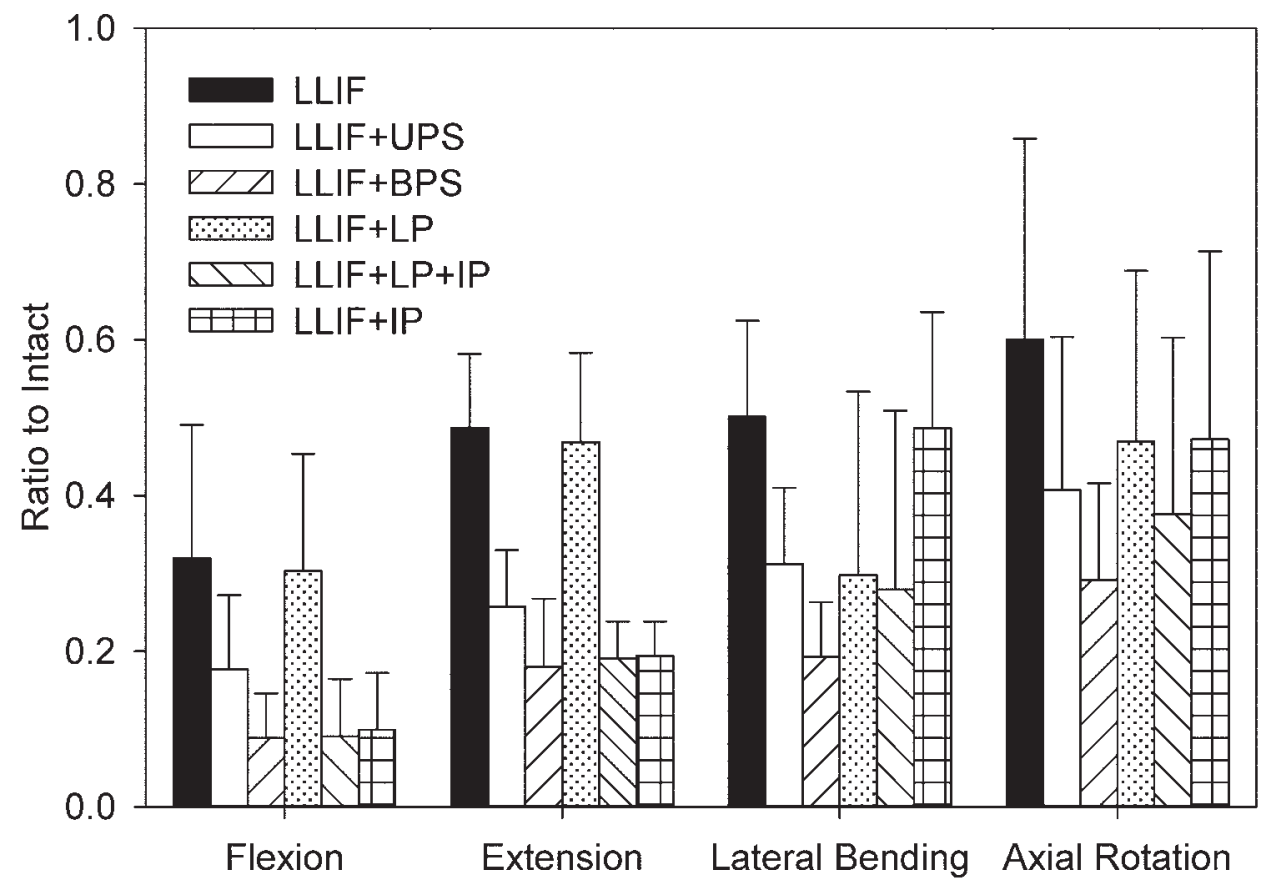

FIG. 3. Bar graph showing the mean normalized L3-4 ROM during each condition of instrumentation. Error bars show the SD. 
TABLE 2. The mean ROM for intact and instrumented constructs during each loading mode*

\begin{tabular}{lcccc}
\hline \multicolumn{1}{c}{ Construct } & Flexion & Extension & $\mathrm{LB}$ & $\mathrm{AR}$ \\
\hline Intact & $4.8 \pm 1.7$ & $4.8 \pm 1.5$ & $5.7 \pm 1.8$ & $2.7 \pm 1.3$ \\
\hline LLIF & $1.6 \pm 1.1$ & $2.3 \pm 0.7$ & $2.8 \pm 1.0$ & $1.5 \pm 0.8$ \\
\hline LLIF + UPS & $0.9 \pm 0.6$ & $1.2 \pm 0.5$ & $1.7 \pm 0.7$ & $1.0 \pm 0.6$ \\
\hline LLIF + BPS & $0.4 \pm 0.3$ & $0.9 \pm 0.5$ & $1.0 \pm 0.4$ & $0.7 \pm 0.4$ \\
\hline LLIF + LP & $1.5 \pm 1.0$ & $2.2 \pm 0.7$ & $1.7 \pm 1.5$ & $1.2 \pm 0.7$ \\
\hline LLIF + LP + IP & $0.5 \pm 0.5$ & $0.9 \pm 0.3$ & $1.6 \pm 1.4$ & $0.9 \pm 0.7$ \\
\hline LLIF + IP & $0.5 \pm 0.5$ & $0.9 \pm 0.3$ & $2.7 \pm 1.1$ & $1.2 \pm 0.8$ \\
\hline
\end{tabular}

* Values are expressed as degrees $\pm 1 \mathrm{SD}$.

retroperitoneal approach, in which a powerful light system, new retractors, and electromyography were combined in a minimally invasive procedure that allowed the insertion of an interbody implant through the lateral aspect of the intervertebral disc space. ${ }^{32}$ Several clinical studies involving LLIF have been reported in the medical literature, including more than 1700 patients with good outcomes and low complication rates. ${ }^{1,10,11,20,22,27,35}$, 36,41,43-45 To date, biomechanical studies evaluating the performance of LLIF have generally demonstrated improved stability with LLIF compared with other lumbar interbody fusion procedures, improved biomechanical performance with an interbody implant placed using the LLIF approach without supplemental fixation compared with the intact condition, and further significant improvements in LLIF construct stability following the application of supplemental fixation. . $^{2,3,5,12,13,21,31,32}$

In addition to investigating the biomechanical effects of an interbody implant and an interbody implant supplemented with posterior screw instrumentation placed using the LLIF approach, the current study is one of very few to include both IP and LP supplemental fixation. The current study demonstrates the following outcomes.

1) Placement of an interbody implant using the LLIF approach without any supplemental fixation significantly decreased the ROM compared with the intact condition in all directions of loading.

2) Addition of BPS to the LLIF construct demonstrated the greatest ROM reduction versus all combinations of LLIF and instrumentation in all directions tested.

3) The LLIF + UPS construct had a performance that was intermediate between LLIF and LLIF + BPS constructs in all directions tested.

4) The LP demonstrated poor biomechanical performance during flexion and extension, significant support for the LLIF construct in lateral bending, and equivalent performance compared with LLIF + UPS in lateral bending and axial rotation.

5) The stabilizing potential of just an IP with the LLIF construct appeared poor during lateral bending, moderate during axial rotation, and good during flexion and extension.

6) The LLIF + LP + IP construct demonstrated biomechanical performance comparable to that of the gold standard LLIF + BPS construct.
The finding of significantly reduced ROM with an interbody implant placed using the LLIF approach without any supplemental fixation compared with the intact condition indirectly supports the underlying hypothesis that the LLIF approach offers a significant degree of inherent stability, probably derived from reduced tissue resection and a larger footprint of the interbody implant. Oliveira et al. ${ }^{25}$ reported safe clinical efficacy using a spacer and an LLIF approach with recombinant human bone morphogenetic protein-2 for treatment of degenerative disc disease. This finding is also in general agreement with findings of previous in vitro biomechanical studies, but with some notable differences. As part of a recent biomechanical investigation, Basra et al. ${ }^{2}$ compared an LLIF construct with LLIF + UPS and LLIF + BPS constructs. Whereas the current study demonstrated significant differences in all directions tested between the LLIF construct and the intact condition, Basra et al. found ROM reductions only in flexion-extension and lateral bending directions. Additionally, the ROM for the LLIF construct was no different from that of the LLIF + UPS construct in any direction in their study, whereas in the current study the LLIF + UPS construct reduced ROM in all directions except axial rotation. Similar to the findings of the current study, their results showed ROM differences between the LLIF construct and LLIF + BPS constructs for all directions tested.

With regard to LP fixation, Nayak et al. ${ }^{24}$ biomechanically compared this condition to a BPS condition in a 2-level (L3-4, L4-5) LLIF setting. They reported significantly reduced ROM with the LLIF + BPS construct compared with the LLIF + LP construct in flexion-extension and lateral bending at both index levels. In comparison, the current study demonstrated a significant reduction in ROM for the same conditions in flexion and extension only.

Few previous biomechanical studies have evaluated the stability of an IP fixation device with or without supplemental fixation following the LLIF approach. Doulgeris et al. ${ }^{12}$ compared LLIF, LLIF + IP, and LLIF + BPS constructs in L1-2 segments. Their study showed significant ROM reduction with the LLIF + IP construct versus the LLIF construct in flexion-extension and lateral bending, whereas in the current study the addition of the IP to the LLIF construct reduced angular motion only in flexionextension. Their study also reported no differences between LLIF + IP and LLIF + BPS constructs, whereas the current study demonstrated differences between the same conditions in lateral bending. Possible factors contributing to these differences include the use of single segments and a lower-end load limit of $5 \mathrm{Nm}$ by Doulgeris et al., compared with L2-5 specimens tested to a 7.5-Nm load limit in all directions in the current study.

In a lumbar multisegment LLIF study, Fogel et al. ${ }^{13}$ previously compared traditional UPS and BPS supplemental fixation with that of IP alone and with combined IP + LP constructs. Data from our current study agree closely with their findings, including the observation that supplemental IP or LP fixation alone or in combination with an LLIF construct does not produce stability comparable to that of the LLIF + BPS construct; however, application of IP + LP + LLIF creates a construct that is statistically equivalent to the gold standard. Compared with the LLIF + IP 
construct, the LLIF + LP construct demonstrated reduced $\mathrm{ROM}$ in flexion-extension, greater ROM in lateral bending, and equivalency in axial rotation. In contrast, Fogel et al. reported that the LLIF + IP construct was less rigid in lateral bending and axial rotation than the LLIF + LP construct.

Limitations of the current study include the use of standardized comparative tests that do not replicate muscle activation and reflect acute stability only. Thus, additional device loading due to muscle force application and/or variations in patient tissue and bone quality may affect device performance in vivo. Additional and longer-term clinical studies are required to confirm the current findings in the clinical setting. Uncontrolled variables (e.g., differences in test specimens, surgical technique, implant design, and application of study protocols) may contribute to differences between the current and previous similar studies.

\section{Conclusions}

Biomechanically, the LLIF construct significantly reduced ROM in all directions of loading compared with the intact spine, indicating an inherent measure of stability with the approach alone. The addition of an LP did not increase the stability of the LLIF construct during flexion or extension. However, supplementing an LLIF construct with both LP and IP resulted in biomechanical performance similar to that of the gold standard LLIF + BPS construct in all directions of loading. Further biomechanical studies are warranted for comparisons among different lumbar interbody fusion techniques.

\section{References}

1. Anand N, Rosemann R, Khalsa B, Baron EM: Mid-term to long-term clinical and functional outcomes of minimally invasive correction and fusion for adults with scoliosis. Neurosurg Focus 28(3):E6, 2010

2. Basra S, Bucklen B, Muzumdar A, Khalil S, Gudipally M: A novel lateral lumbar integrated plate-spacer interbody implant: in vitro biomechanical analysis. Spine J 15:322-328, 2015

3. Bess RS, Cornwall GB, Vance RE, Bachus KN, Brodke DS: Biomechanics of lateral arthrodesis, in Goodrich JA, Volcan IJ (eds): Extreme Lateral Interbody Fusion (XLIF). St. Louis: Quality Medical Publishing, 2008, pp 31-40

4. Billinghurst J, Akbarnia BA: Extreme lateral interbody fusion-XLIF. Curr Orthop Pract 20:238-251, 2009

5. Cappuccino A, Cornwall GB, Turner AW, Fogel GR, Duong HT, Kim KD, et al: Biomechanical analysis and review of lateral lumbar fusion constructs. Spine (Phila Pa 1976) 35 (26 Suppl):S361-S367, 2010

6. Crawford NR, Brantley AG, Dickman CA, Koeneman EJ: An apparatus for applying pure nonconstraining moments to spine segments in vitro. Spine (Phila Pa 1976) 20:20972100,1995

7. Crawford NR, Dickman CA: Construction of local vertebral coordinate systems using a digitizing probe. Technical note. Spine (Phila Pa 1976) 22:559-563, 1997

8. Crawford NR, Peles JD, Dickman CA: The spinal lax zone and neutral zone: measurement techniques and parameter comparisons. J Spinal Disord 11:416-429, 1998

9. Crawford NR, Yamaguchi GT, Dickman CA: A new technique for determining 3-D joint angles: the tilt/twist method. Clin Biomech (Bristol, Avon) 14:153-165, 1999
10. Dakwar E, Cardona RF, Smith DA, Uribe JS: Early outcomes and safety of the minimally invasive, lateral retroperitoneal transpsoas approach for adult degenerative scoliosis. Neurosurg Focus 28(3):E8, 2010

11. Deluzio KJ, Lucio JC, Rodgers WB: Value and cost in less invasive spinal fusion surgery: lessons from a community hospital. SAS J 4:37-40, 2010

12. Doulgeris JJ, Aghayev K, Gonzalez-Blohm SA, Lee WE III, Vrionis FD: Biomechanical comparison of an interspinous fusion device and bilateral pedicle screw system as additional fixation for lateral lumbar interbody fusion. Clin Biomech (Bristol, Avon) 30:205-210, 2015

13. Fogel GR, Parikh RD, Ryu SI, Turner AW: Biomechanics of lateral lumbar interbody fusion constructs with lateral and posterior plate fixation: laboratory investigation. J Neurosurg Spine 20:291-297, 2014

14. Goh JC, Wong HK, Thambyah A, Yu CS: Influence of PLIF cage size on lumbar spine stability. Spine (Phila Pa 1976) 25:35-40, 2000

15. Han X, Zhu Y, Cui C, Wu Y: A meta-analysis of circumferential fusion versus instrumented posterolateral fusion in the lumbar spine. Spine (Phila Pa 1976) 34:E618-E625, 2009

16. Harris BM, Hilibrand AS, Savas PE, Pellegrino A, Vaccaro AR, Siegler S, et al: Transforaminal lumbar interbody fusion: the effect of various instrumentation techniques on the flexibility of the lumbar spine. Spine (Phila Pa 1976) 29:E65E70, 2004

17. Heth JA, Hitchon PW, Goel VK, Rogge TN, Drake JS, Torner JC: A biomechanical comparison between anterior and transverse interbody fusion cages. Spine (Phila Pa 1976) 26:E261-E267, 2001

18. Kim SM, Lim TJ, Paterno J, Park J, Kim DH: Biomechanical comparison: stability of lateral-approach anterior lumbar interbody fusion and lateral fixation compared with anteriorapproach anterior lumbar interbody fusion and posterior fixation in the lower lumbar spine. J Neurosurg Spine 2:62-68, 2005

19. Knight RQ, Schwaegler P, Hanscom D, Roh J: Direct lateral lumbar interbody fusion for degenerative conditions: early complication profile. J Spinal Disord Tech 22:34-37, 2009

20. Kueper J, Fantini GA, Walker BR, Aichmair A, Hughes AP: Incidence of vascular complications during lateral lumbar interbody fusion: an examination of the mini-open access technique. Eur Spine J 24:800-809, 2015

21. Laws CJ, Coughlin DG, Lotz JC, Serhan HA, Hu SS: Direct lateral approach to lumbar fusion is a biomechanically equivalent alternative to the anterior approach: an in vitro study. Spine (Phila Pa 1976) 37:819-825, 2012

22. Marchi L, Abdala N, Oliveira L, Amaral R, Coutinho E, Pimenta L: Stand-alone lateral interbody fusion for the treatment of low-grade degenerative spondylolisthesis. ScientificWorldJournal 2012:456346, 2012

23. McAfee PC: Interbody fusion cages in reconstructive operations on the spine. J Bone Joint Surg Am 81:859-880, 1999

24. Nayak AN, Gutierrez S, Billys JB, Santoni BG, Castellvi AE: Biomechanics of lateral plate and pedicle screw constructs in lumbar spines instrumented at two levels with laterally placed interbody cages. Spine J 13:1331-1338, 2013

25. Oliveira L, Marchi L, Coutinho E, Abdala N, Pimenta L: The use of rh-BMP2 in standalone extreme lateral interbody fusion (XLIF): clinical and radiological results after 24 months follow-up. World Spinal Column J 1:19-25, 2010

26. Oppenheimer JH, DeCastro I, McDonnell DE: Minimally invasive spine technology and minimally invasive spine surgery: a historical review. Neurosurg Focus 27(3):E9, 2009

27. Ozgur BM, Agarwal V, Nail E, Pimenta L: Two-year clinical and radiographic success of minimally invasive lateral transpsoas approach for the treatment of degenerative lumbar conditions. SAS J 4:41-46, 2010 
28. Ozgur BM, Aryan HE, Pimenta L, Taylor WR: Extreme lateral interbody fusion (XLIF): a novel surgical technique for anterior lumbar interbody fusion. Spine J 6:435-443, 2006

29. Panjabi MM: Biomechanical evaluation of spinal fixation devices: I. A conceptual framework. Spine (Phila Pa 1976) 13:1129-1134, 1988

30. Pavlov PW, Spruit M, Havinga M, Anderson PG, van Limbeek J, Jacobs WC: Anterior lumbar interbody fusion with threaded fusion cages and autologous bone grafts. Eur Spine J 9:224-229, 2000

31. Perez-Orribo L, Kalb S, Reyes PM, Chang SW, Crawford NR: Biomechanics of lumbar cortical screw-rod fixation versus pedicle screw-rod fixation with and without interbody support. Spine (Phila Pa 1976) 38:635-641, 2013

32. Pimenta L, Turner AW, Dooley ZA, Parikh RD, Peterson MD: Biomechanics of lateral interbody spacers: going wider for going stiffer. ScientificWorldJournal 2012:381814, 2012

33. Pitzen T, Geisler FH, Matthis D, Müller-Storz H, Steudel WI: Motion of threaded cages in posterior lumbar interbody fusion. Eur Spine J 9:571-576, 2000

34. Ploumis A, Wu C, Fischer G, Mehbod AA, Wu W, Faundez A, et al: Biomechanical comparison of anterior lumbar interbody fusion and transforaminal lumbar interbody fusion. J Spinal Disord Tech 21:120-125, 2008

35. Rodgers WB, Cox CS, Gerber EJ: Early complications of extreme lateral interbody fusion in the obese. J Spinal Disord Tech 23:393-397, 2010

36. Rodgers WB, Gerber EJ, Patterson J: Intraoperative and early postoperative complications in extreme lateral interbody fusion: an analysis of 600 cases. Spine (Phila Pa 1976) 36:2632, 2011

37. Sohn MJ, Kayanja MM, Kilinçer C, Ferrara LA, Benzel EC: Biomechanical evaluation of the ventral and lateral surface shear strain distributions in central compared with dorsolateral placement of cages for lumbar interbody fusion. J Neurosurg Spine 4:219-224, 2006

38. Strube P, Hoff E, Hartwig T, Perka CF, Gross C, Putzier M: Stand-alone anterior versus anteroposterior lumbar interbody single-level fusion after a mean follow-up of 41 months. J Spinal Disord Tech 25:362-369, 2012

39. Subach BR, Copay AG, Martin MM, Schuler TC: Anterior lumbar interbody implants: importance of the interdevice distance. Adv Orthop 2011:176497, 2011

40. Tencer AF, Hampton D, Eddy S: Biomechanical properties of threaded inserts for lumbar interbody spinal fusion. Spine (Phila Pa 1976) 20:2408-2414, 1995

41. Tormenti MJ, Maserati MB, Bonfield CM, Okonkwo DO, Kanter AS: Complications and radiographic correction in adult scoliosis following combined transpsoas extreme lateral interbody fusion and posterior pedicle screw instrumentation. Neurosurg Focus 28(3):E7, 2010

42. Tsantrizos A, Andreou A, Aebi M, Steffen T: Biomechanical stability of five stand-alone anterior lumbar interbody fusion constructs. Eur Spine J 9:14-22, 2000

43. Waddell B, Briski D, Qadir R, Godoy G, Houston AH, Rudman E, et al: Lateral lumbar interbody fusion for the correction of spondylolisthesis and adult degenerative scoliosis in high-risk patients: early radiographic results and complications. Ochsner J 14:23-31, 2014

44. Wang MY, Mummaneni PV: Minimally invasive surgery for thoracolumbar spinal deformity: initial clinical experience with clinical and radiographic outcomes. Neurosurg Focus 28(3):E9, 2010

45. Youssef JA, McAfee PC, Patty CA, Raley E, DeBauche S, Shucosky E, et al: Minimally invasive surgery: lateral approach interbody fusion: results and review. Spine (Phila Pa 1976) 35 (26 Suppl):S302-S311, 2010

46. Zander T, Rohlmann A, Klöckner C, Bergmann G: Influence of graded facetectomy and laminectomy on spinal biomechanics. Eur Spine J 12:427-434, 2003

\section{Disclosures}

Dr. Chang receives royalties from, and is a consultant to, Globus Medical, Inc.; he receives royalties from Biomet/Lanx; consulting fees from LDR Holding Corp.; and educational grants from Medtronic, Inc. Mr. Singh is an employee of Medtronic, Inc. Dr. Crawford is currently an employee of Globus Medical, Inc. This study was funded by Medtronic, Inc., Memphis, TN.

\section{Author Contributions}

Conception and design: Chang, Crawford. Acquisition of data: Reis, Reyes, Altun. Analysis and interpretation of data: Kelly, Newcomb, Crawford. Drafting the article: Kelly, Reis, Altun, Newcomb, Singh, Chang, Crawford. Critically revising the article: Kelly, Singh, Crawford. Reviewed submitted version of manuscript: Kelly, Newcomb, Singh, Chang, Crawford. Statistical analysis: Newcomb. Administrative/technical/material support: Kelly, Reyes, Singh. Study supervision: Crawford.

\section{Correspondence}

Brian P. Kelly, c/o Neuroscience Publications, Barrow Neurological Institute, St. Joseph's Hospital and Medical Center, 350 W Thomas Rd., Phoenix, AZ 85013. email: brian.kelly@dignity health.org. 